\title{
Master the New Educational Technology and Realize the Modernization of College Education
}

\author{
Jiying Yang
}

Yunnan Open University, Kunming, Yunnan 650223, China

\begin{abstract}
In recent years, with the continuous development of modern educational technology, it has played an important role in college education and is a basic way to promote the development of college education. The development of modern educational technology and education and teaching reform complement each other and form a joint The fundamental problem of the development of educational technology in colleges and universities, in order to realize the modernization of college education and occupy the commanding heights of modern education, it is necessary to have a deep understanding of the influence of modern educational technology in the educational activities of colleges and universities. This article explores this.
\end{abstract}

Keywords: Educational Technology; Teaching Reform; Educational Modernization

Rejuvenating the country through science and education is an important measure for the development of countries in the world. With the continuous development of Internet technology, more and more new technical methods have begun to enter the classroom, which has caused earth-shaking changes in teaching methods, teaching scale and teaching scope. Under the current educational situation, it is a very important task for educational technology workers to study educational technology theory and deepen teaching reform.

\section{Modern educational technology is a breakthrough to deepen the reform of education and teaching}

Modern educational technology takes pedagogy theory as the foundation, adopts modern scientific and technological achievements and systematic scientific viewpoints and methods, and explores the means to enhance teaching effect and the theory of optimizing teaching process. In the development of college education, modern educational technology provides In particular, information technology has changed the way human beings use information processing and transmission, so it has a great impact on the educational methods of colleges and universities, and has realized the optimization of college educational resources. With the in-depth development of information technology and the development of educational technology, there is a broader space for deployment. Therefore, we should use this as a breakthrough in the development of modern education, actively promote the construction and reform of college education, and combine the needs of educational development in the new era to create a new chapter in the modernization of educational technology and college education.

\section{Modern educational technology is an important guarantee for improving the quality of education and teaching in colleges}

There is a close relationship between the quality of college education and the quality of talent training, which is the key to the cultivation of high-quality talents. The wide application of modern educational technology can promote the improvement of teaching quality, so it has gradually become a new growth point of teaching quality. From the perspecCopyright (C) 2020 Jiying Yang

doi: 10.18282/le.v9i7.1519

This is an open-access article distributed under the terms of the Creative Commons Attribution Non-Commercial License

(http://creativecommons.org/licenses/by-nc/4.0/), which permits unrestricted non-commercial use, distribution, and reproduction in any medium, provided the original work is properly cited. 
tive of cognitive theory, modern educational technology truly realizes the integration of teaching media and methods. The angle stimulates learners' senses, mobilizes learners' desire for knowledge to a limited extent, and stimulates learners' enthusiasm and creativity in learning. At the same time, modern technology brings more abundant learning resources, so that learners can be the fastest Under the speed, master the latest teaching content in the most flexible way. The emergence of modern educational technology has truly realized teaching students in accordance with their aptitude, and through the updating of teaching methods and teaching methods, the overall development of education has been promoted.

\section{Modern educational technology is the main symbol of the establishment of prestigious universities}

The reason why prestigious universities have a strong appeal and brand effect is that they are always at the forefront of the education front. The education level of an institution is closely related to the application level of modern educational technology. Only when the education system of the institution is fully integrated Only with modern educational technology can the teaching of colleges and universities achieve the overall optimization, so as to maximize the advantages of modern educational technology, and this is also the main symbol of famous universities.

\section{Main tasks in the new era}

\subsection{Realize the localized development of educational technology theory}

In the application of excellent educational concepts, it is also necessary to pay attention to the adaptability of local educational development. Therefore, when applying new educational technologies in our country, we should learn from them and innovate on them. On the one hand, relevant theories should be optimized in light of the national conditions, and education technology should be innovated and surpassed on the basis of accumulating certain experience. Through innovative research on the theory, system and mechanism of informatization education, the localized development of educational technology theory is realized, and an educational technology theoretical system with Chinese characteristics is formed.

\subsection{Implement the people-oriented education philosophy}

As the media of education, new educational technology should become an important tool for teacher education, not the main body of teaching. In education, the media should not be overemphasized and the learning process should not be ignored. Instead, people-oriented education concepts should be followed, and new ones should be used scientifically and rationally. Educational technology.

\subsection{Fully stimulate the potential of educational information technology and efficiently integrate information technology and subject teaching}

While integrating information technology into education, it is necessary to strengthen the interaction between the real situation and the virtual learning space, so that the learning content of the two can be effectively integrated, so that students can experience the generation and development of real knowledge and produce a deeper understanding. Give full play to the teaching function of information technology to optimize the quality of education.

\subsection{Promote balanced development of education with educational technology}

Although there is no hierarchy in education, it is undeniable that there are certain differences in educational resources in different regions, and people in different regions have different opportunities to receive education. The application of new educational technology should reduce the difference in teaching resources between urban and rural areas and between regions, and provide equal educational opportunities for all students. In particular, the development of digital education resources can provide more powerful support for the construction of informatization education in rural and remote poor areas.

\section{Concluding remarks}


Educational reform is like fighting with the army. When arranging troops, we must pay attention to strategy and tactics and strive to seize the commanding heights. The key to educational reform is to seize the commanding heights. For this reason, education should focus on the use of strategies and methods, and use advanced educational concepts and Educational technology optimizes the quality of teaching so as to realize the modernization of education. For the continuous innovation of modern educational technology, teachers should adopt a positive attitude to accept the integration of modern educational technology, scientifically use educational technology and give full play to its teaching advantages, so as to improve the quality of teaching talents, deliver high-quality talents for national construction, and promote my country's modernization Implementation of the goal of a powerful country.

\section{References}

1. Guo Ce, Gao Jiabin, Zhao Yitong, Li Jiahui, Li Yang. Research on Innovation and Entrepreneurship Education in Higher Vocational Colleges under the Background of Educational Modernization[J]. Economist, 2020(10): 178-179.

2. Wang Pengli, Qi Peng. Analysis of the basic ways of modernizing the governance system and governance capabilities of higher vocational colleges[J]. Scientific Consulting (Science \& Technology Management), 2020(10): 79.

3. Xie Li. Make up for shortcomings, activate power, strengthen connotation, increase benefits, and strive to run fair and quality vocational education [J]. Chinese Vocational and Technical Education, 2020 (27): 5-11. 